\title{
An Investigation of the Influence of Changing Energy Volume Densities to Produce a Complete Process Parameter Window for Selective Laser Melting of Scalmalloy
}

\author{
Celine Turangi ${ }^{*}$, Florian Haslich ${ }^{2}$, Tim Pasang1 \\ ${ }^{1}$ School of Engineering, Computing and Mathematical Sciences, Auckland University of Technology, \\ Auckland 1010, New Zealand \\ ${ }^{2}$ Fraunhofer Institute for Manufacturing Technology and Advanced Material IFAM, Dresden, Germany \\ Branch Lab Dresden Winterbergstrasse 28, Dresden 01277, Germany.
}

*Corresponding author:

E-mail: cjturangi@hotmail.com

\begin{abstract}
The scandium-zirconium modified aluminum alloy Scalmalloy is additively manufactured using Selective Laser Melting in the Renishaw AM 400 SLM machine. THE optimal SLM process parameter window concerning relative densities exceeding $99 \%$ was investigated. Scalmalloy powder was characterized concerning particle morphology, qualitative particle size distribution, and inner gas pores. Full available SLM laser power of Renishaw AM 400 SLM machine was applied to increase productivity as much as possible. Archimedes density method and metallographic cross-sections were used to determine relative densities, whereby all samples printed exceeded 99\%. THE optimal SLM process parameter window for the laser power of $400 \mathrm{~W}$ was found to be in the range of $40-110 \mathrm{~J} / \mathrm{mm} 3$ where scan speed is doubled compared to other literature using $200 \mathrm{~W}$, thus productivity is greatly increased. Microhardness testing was also performed on all samples and showed the successful suppression of $\mathrm{Al}_{3}\left(\mathrm{Sc}_{1}-\mathrm{xZ} \mathrm{r}_{\mathrm{x}}\right)$ precipitates, whereby subsequent age hardening may be performed post-process.
\end{abstract}

Keywords: Scalmalloy, SLM, parameter, energy volume density

\section{Introduction}

Aluminum alloys are one of the most widely used metallic alloys in the world as they possess low density, high strength, corrosion resistance, and excellent electrical properties (Olakanmi, Cochrane \& Dalgarno, 2015). Aluminum alloys are classified as either heat treatable (2xxx, 6xxx, 7xxx and 8xxx Al series) or non-heat-treatable alloys (1xxx, 3xxx, 4xxx, 5xxx), where heat and plastic deformation can be used to strengthen the alloy, respectively (Polmear et al., 2017; Zahner, 2019). Aluminum is commonly used in traditional manufacturing methods such as casting, extrusion, and forging, but recently it has been introduced into Additive Manufacturing (AM). AM produces components by layering material, one after another until a component is built based upon 3D computer model data (Olakanmi, Cochrane \& Dalgarno 2015). AM can quickly manufacture geometrically complex and lightweight components over traditional methods (Singh, Ramakrishna \& Singh 2017). Selective laser melting (SLM) is the most common method in AM to process Al alloys, whereby, a component is built inside an inert chamber using powdered material (Aboulkhair et al., 2019; Aversa et al., 2019).

SLM-processed components possess outstanding quality, properties, and performance due to the rapid melting and solidification of the molten metal during SLM (Harun et al., 2018). However, SLM parts can develop defects that can detrimentally affect the quality of the part,

How to cite:

Turangi, C., Haslich, F., \& Pasang, T. (2020). An investigation of the influence of changing energy volume densities to produce a complete process parameter window for selective laser melting of scalmalloy. $1^{\text {st }}$ International Conference Eco-Innovation in Science, Engineering, and Technology. NST Proceedings. pages 21-33. doi: 10.11594/ nstp.2020.0503 
hence minimization of defects is important and is highly dependent upon the process parameters and material being used (Maamoun et al., 2018; Zhang, Li \& Bai 2017). SLM process parameters control the conditions produced within the machine and are predetermined by the operator of the machine. The influencing process parameters are scanning speed $(\mathrm{mm} / \mathrm{s})$, laser power (W), build direction, hatch spacing, hatch angle, and layer thickness. Scanning speed and laser power are parameters that control energy input, whilst build direction and hatch angle can influence anisotropic behavior, performance, and tensile properties. (Hanzl et al., 2015; Maamoun et al., 2018). Hatch spacing affects dimensional accuracy and surface flatness and layer thickness may also have an influence, however, with certain materials it may not affect at all. (Hanzl et al., 2015; Maamoun et al., 2018; Yap et al., 2015). For the powdered material, good flowability, even surface morphology, even size distribution, and normal composition are desirable (Chituc, 2017; DebRoy et al., 2018). Spherical particle shape and narrower size distribution are optimal with a typical powder particle size usually within 10-60 $\mu \mathrm{m}$. Small particle size and regular morphology yield a finer microstructure with better surface finish, thinner layers, better performance, and better printability (Li et al., 2019; Vock et al., 2019).

The interest to develop high strength Al alloys for Selective Laser Melting (SLM) has grown in recent years with the growing interest in Additive Manufacturing (AM) processes. However, challenges to control the high reflectivity, oxidation tendencies, poor powder flowability, freezing range, and thermal conductivity properties of $\mathrm{Al}$ alloys have caused major delays. The heattreatable 2xxx, 6xxx, and 7xxx series can barely be processed in SLM as these Al alloys have solidification cracking tendencies and possess unstable elements such as Zinc (Zn), Mg, and Lithium (Li), which evaporate during the SLM process. The Al-Si alloys (4000 series) as Silicon (Si) can reduce cracking and cause high grain refinement. However, high anisotropic behavior where cracking can develop along the build direction is evident (Aversa et al., 2019). Wrought alloys have also experimented in SLM. The 5xxx series Al-Mg alloys offer good corrosion resistance and can produce high solid solution hardening and with Scandium (Sc) and Zirconium (Zr), it can produce stable precipitates and act as deterrents of cracking during rapid solidification, thus these alloys are thought to be both age-hardenable and work-hardenable (Kaiser et al., 2014; Spierings, Dawson, Heeling, et al., 2017). Scalmalloy is an Al-Mg-Sc alloy specifically developed for SLM and has been in development for almost twenty years by Airbus Group Innovation. Scalmalloy has a fined grain microstructure with columnar growth along the build direction surpassing that of $\mathrm{Al}$ and $\mathrm{Al}-\mathrm{Mg}$ castings and SLM-processed Al-Si alloys. A supersaturated solid solution also forms under the laser during SLM. This in turn gives rise to the formation of $\mathrm{Al}_{3}(\mathrm{Sc}, \mathrm{Zr})$ precipitates, and a bimodal grain size distribution with clear coarse and fine-grained regions is formed. These precipitates improve strength and preserve toughness and ductility in the as-built state and the presence of Zirconium (Zr) further increases its strength where a lesser amount of Sc may be sufficient (Spierings et al., 2017; Spierings et al., 2016).

Scalmalloy has been well-documented in its ability to be processed by SLM. Schmidtke et al. (2011) were the first to explore a suitable processing window for Scalmalloy to determine whether it could withstand the SLM conditions of rapid cooling and solidifying and high temperatures. Large hatch distances and increasing scan speeds caused a loss in density, and incomplete melting occurred due to the material itself or process parameters. Anisotropy was also reported to be low with only a $1.5 \%$ and $3 \%$ difference in $0 \mathrm{o}$ and 450 build directions and elongation and change in area was also negligibly low. Hardness was improved from $105 \mathrm{Hv}$ to $177 \mathrm{Hv}$ due to $\mathrm{Al}_{3} \mathrm{Sc}$ precipitates occurring during the SLM process, whereby the addition of $\mathrm{Zr}$ and $\mathrm{Mg}$ further increased precipitation hardening. Lastly, a hyper eutectic Al-Sc composition was attained. Best et al. (2018) studied the mechanical anisotropy for the bi-modal microstructure of Scalmalloy. Anisotropy was low on a macroscopic scale, and although some microscopic discrepancies were found, these could be improved with annealing further supporting 
Schmidtke et al. (2011) findings. In a study by Spierings et al. (2016), and SLM processing window was explored. The laser power of $200 \mathrm{~W}$ was used to counter the high reflectivity of Aluminium. Energy densities between 75 and $240 \mathrm{~J} / \mathrm{mm} 3$ and hatch distances between $135 \mathrm{um}$ and $165 \mathrm{um}$ were also used. It was found that a lower energy density caused a finer grain, yet the bi-modal structure remained. In a study by Koutny et al. (2018), a processing window was explored for Scalmalloy with a higher Sc content of greater than 1\%. Cube specimens were built with varying process parameters. Laser power was between 325 and $400 \mathrm{~W}$, laser scanning speed was between $100-1400 \mathrm{~mm} / \mathrm{s}$ and hatch distance and layer thickness were fixed at $100 \mathrm{um}$ and $60 \mathrm{um}$, respectively. Large pores became apparent for scanning speeds between $100-500 \mathrm{~mm} / \mathrm{s}$.

However, increasing scan speed to $1100 \mathrm{~mm} / \mathrm{s}$ with EVD of $55 \mathrm{~J} / \mathrm{mm} 3$ produce fusion defects. EDV between $60-70 \mathrm{~J} / \mathrm{mm} 3$ gave the best density results and when laser power was between 325 and $375 \mathrm{~W}$ with laser scanning speed. An overview is given of the influences of the process parameters in SLM. Scalmalloy can be well- processed in SLM. The higher Sc content indicates that this could lead to higher tensile values, but with greatly lowered ductility. In another study, an Al-Mg-Sc-Zr alloy with high Mg content of $6.2 \%$ was used to determine a suitable processing window. Relative density increased for an increase in laser power, while the scan strategy did not affect. Although, island scanning was more favorable than rotary scanning as this produced a more consistent powder bed however, island scanning showed irregular and vague weld pool, while rotary scanning was uniform throughout. High EVD can cause micropores to be filled easily as dynamic viscosity is lowered, but high temperatures can also cause balling. It was reported that when EVD was increased from $81 \mathrm{~J} / \mathrm{mm} 3$ to $97 \mathrm{~J} / \mathrm{mm} 3$ less balling occurred. With continually increasing EVD, almost no balling occurred, and surfaces became smooth (Li et al. 2017). Another study by Li et al. (2019), increasing laser power with fixed scan speed was seen to increase density. While fixed laser power with increasing scan speed resulted in a lower density. Micropores occurred when laser power was 200W and scan speed was $800 \mathrm{~mm} / \mathrm{s}$ caused by insufficient melting due to low energy input. When laser power was increased to $300 \mathrm{~W}$ and scan speed was $500 \mathrm{~mm} / \mathrm{s}$ the micropores declined. At a laser power of $400 \mathrm{~W}$, even fewer micropores occurred. It was found that $400 \mathrm{~W}$ with a scan speed of $800 \mathrm{~mm} / \mathrm{s}$ resulted in almost full density samples. In the current literature, it was reported that the influencing process parameters are seen to be scan speed, laser power, hatch distance, whereas build direction, scan strategy, and layer thickness do not have a significant effect. However, most studies used laser power of $200 \mathrm{~W}$, while only a few had higher laser power, the Scalmalloy had a different composition than the powder used in this research. Therefore, this paper investigates a suitable processing window for Scalmalloy in a Renishaw AM 400 SLM machine. Processing parameters are also investigated to determine whether high scan speed, high laser power, and relatively low energy density may achieve optimal dimensional accuracy, density, and productivity, while allowing for subsequent ageing.

\section{Experimental Procedure Scalmalloy powder composition and characterization}

Scalmalloy powder was supplied by LPW Technology and its chemical composition can be viewed in table 2 Sieve analysis is $0 \mathrm{wt} \%$ of the particles are larger than $63 \mathrm{um}$ and laser size diffraction resulted in 6 vol\% particles are smaller than $20 \mathrm{um}$. Powder morphology was examined using a Hitachi SU-70 scanning electron microscope (SEM). A small amount of powder was distributed on an adhesive carbon pad to ensure electric conductivity and acceleration of $5 \mathrm{kV}$ and a secondary electron detector was applied for high surface sensitivity. Scalmalloy particles were also cold mounted using Struers EpoFix epoxy resin and hardener. Samples were metallographically prepared and examined using an Olympus BX51M optical microscope, whereby three optical micrographs were taken at 100x magnification and all cut particles with visible inner pores and 
the total number of cut particles were counted. To minimize errors, microhardness testing was executed upon circular powder particle cross-sections with similar diameters and indentations with distance from powder particle cross-section edge larger than $2.5 \mathrm{x}$ indentation diagonal length.

Table 1. Chemical composition of scalmalloy by specification and analysis

\begin{tabular}{lllllllllllll}
\hline wt\% & Al & Mg & Sc & Zr & Mn & Si & Fe & Zn & Ti & Cu & V & 0 \\
Max. & bal. & 4.90 & 0.80 & 0.50 & 0.80 & 0.40 & 0.40 & 0.25 & 0.15 & 0.10 & 0.05 & 0.05 \\
$\begin{array}{l}\text { Anal- } \\
\text { ysis. }\end{array}$ & bal. & 4.55 & 0.65 & 0.30 & 0.51 & 0.16 & 0.14 & 0.02 & 0.01 & 0.01 & 0.01 & 0.04 \\
Min. & --- & 4.00 & 0.60 & 0.20 & 0.03 & --- & --- & --- & -- & --- & --- & -- \\
\hline
\end{tabular}

\section{SLM Process}

A Renishaw AM 400 SLM machine was used. It was equipped with a pulsed laser whereby maximum laser power was $400 \mathrm{~W}$. The laser focus diameter was $70 \mu \mathrm{m}$ and the building envelope was $250 \times 250 \times 300 \mathrm{~mm}$ in size. Argon was used as the shielding gas during the SLM process and samples were built on top of a stainless-steel plate $248 \times 248 \mathrm{~mm}$ large with a milled or blasted surface finish. Standard software was used, unless otherwise indicated whereby each layer is hatched bi-directionally before exposing two single scan tracks of contour and then alternating hatch direction by 67o layer-wise. When samples were built, prevailing support structures were removed by cutting them off.

\section{Proceeding parameter for SLM window}

Processing parameters that will remain constant are based on findings by Spierings et al.,2017a; Spierings et al., 2017b; Spierings et al., 2018); Spierings et al., 2016) are based on the same composition of the Scalmalloy powder that will be used in the research on hand. Parameters that will be fixed are laser power, laser focus diameter, layer thickness, scan strategy, and hatch distance. Scan speed and hence energy volume density will be varied accordingly. Energy density can be represented by the following equation (Wong \& Hernandez 2012).

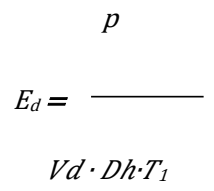

Where $E_{d}$ is energy density $(\mathrm{J} / \mathrm{mm} 3), P$ is laser power $(W), D_{h}$ is hatch spacing $(\mathrm{mm}), T_{1}$ is layer thickness and $V_{d}$ is scanning speed $(\mathrm{mm} / \mathrm{s})$. This equation shows the relationship between scan speed, laser power, and energy density and therefore scan speeds can be calculated based upon chosen energy densities. (Maamoun et al., 2018). As laser power will be doubled from 200W, according to the literature, to $400 \mathrm{~W}$ for this research, layer thickness was chosen as $30 \mu \mathrm{m}$ and hatch distance was chosen as $150 \mu \mathrm{m}$. To verify the processing window presented by Spierings et al. (2016), energy volume densities of $80,120,150,240$, and 280J/mm3 with corresponding scan speeds of $1111,741,593.370$ and $317 \mathrm{~mm} / \mathrm{s}$, respectively, will be investigated in the first build job. As the laser power for this research is increased compared to that of literature, the SLM processing window is shifted. To investigate a complete SLM processing window for relative densities exceeding 99\%, a second build job will be performed with differing energy volume densities and respective scan speeds of $30,45,60,80,100 \mathrm{~J} / \mathrm{mm} 3$ and 2962, 1975, 1481, 1111, $889 \mathrm{~mm} / \mathrm{s}$. The cube sample using $80 \mathrm{~J} / \mathrm{mm} 3$ was built an additional time to confirm indication for SLM inter-build 
reproducibility. For each of the five sets of SLM process parameters, one cube sample on 3mm high support structures were built (figure 1), whereby 5 cube samples were built in one build job. Anisotropy is not investigated in this paper as both Schmidtke et al. (2011) and Best et al., (2018) have indicated that anisotropy is very low for Scalmalloy, therefore all samples were built in a line parallel to $\mathrm{x}$-direction with $20 \mathrm{~mm}$ distances in between each cube and centered on the build platform.

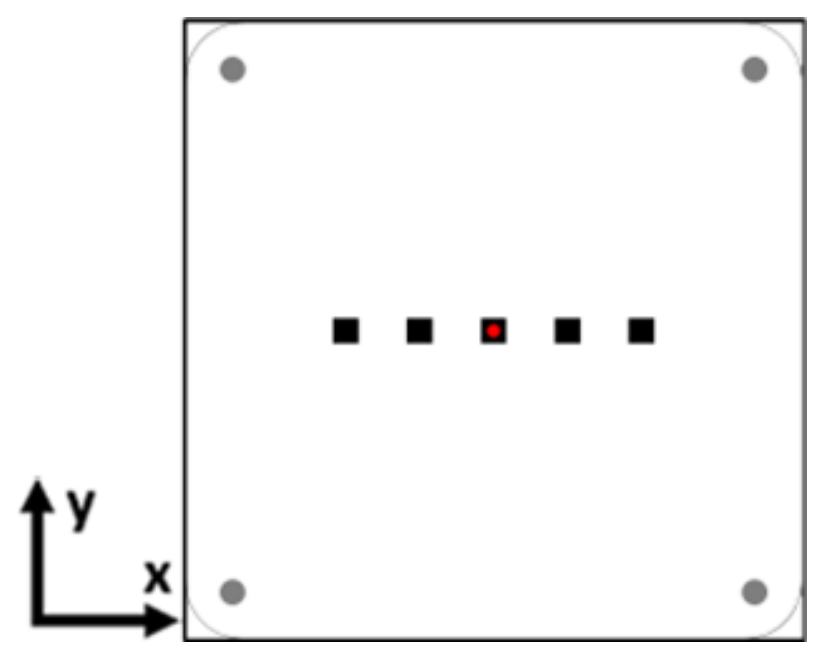

Figure 1. Schematic depicting sample layout on the build platform. X and Y directions are also indicated

\section{Measurement techniques and testing methods}

After samples were built, residual powder and support structures were removed then investigated regarding their dimensional accuracy in $\mathrm{x}$ and $\mathrm{y}$ direction using a micrometer. Lengths of upper cube edges as well as distances between opposing cube faces were measured. Surface quality in the as-built condition was qualitatively examined using SEM. All samples were tested using the Archimedes method. This method allows for high accuracy while also being fast and economical according to Spierings, Schneider \& Eggenberger (2011). A BSM220.4 electronic balance was used with a readability of $0.1 \mathrm{mg}$. The cube samples were weighed in air and secondly in ethanol while being attached to a thin and flexible metallic wire. The temperature dependence of ethanol's density was considered, and each sample was tested three times. Density was calculated using equation (2) where Scalmalloy theoretical density was taken as $2.67 \mathrm{~g} / \mathrm{m} 3$. The cube samples were then metallographically prepared by cutting the samples using a Struers Labotom-3 parallel to building direction $\mathrm{z}$. These were then hot mounted using electrically conductive PolyFast and a Struers LaboPress-3 at $150 \mathrm{oC}$ and $25 \mathrm{kN}$. After, mounted samples were ground with Struers silicon carbide grinding papers of 180, 500, 1200, and 2400 mesh on a Buehler MetaServ rotary grinding machine. Samples were then polished firstly with Struers diamond paste using $6 \mu \mathrm{m}$ on MD-Dac fabric on a Struers LaboPol- 2 polishing machine and then finally with a $3 \mu \mathrm{m}$ diamond suspension. Lastly, these cube cross-section samples were etched with Keller's agent consisting of $2.5 \%$ HNO3, $1.5 \% \mathrm{HCl}, 1 \% \mathrm{HF}$ and balance distilled water. Samples were then visually investigated using an Olympus BX51M optical microscope and ScopePhoto software by ScopeTek. For higher magnifications, SEM was used. To determine inner porosity and relative density, 5 optical images at 50x magnification per sample were analyzed with Image J software as this software is fast and accurate according to Spierings, Schneider \& Eggenberger (2011). Optical micrographs were taken from upper and lower corners as well as from the center of each sample cross-section. Microhardness testing was carried out on all metallographically prepared samples to compare as-built hardness values to powder hardness values. A Leco microhardness tester LM $800 \mathrm{AT}$ with a load of $5 \mathrm{gf}$, 
dwell time of 10 s and optical magnification of 500x measurement of indentations was used. Ten randomly distributed indentations per cross-section were made upon each sample.

$$
\underset{\text { abs }}{\rho=\text { mair }} \cdot \quad \text { meth } \quad \text { eth }
$$

\section{Results and Discussion \\ Power characterization}

SEM of powder revealed particles with spherical morphology and diameters of 5-40 $\mu \mathrm{m}$. Only a small portion of the particles was shaped irregularly with diameters of $2 \mu \mathrm{m}$ or less. Very few elongated particles were detected with dimensions between $60-80 \mu \mathrm{m}$ shown in figure 2 .

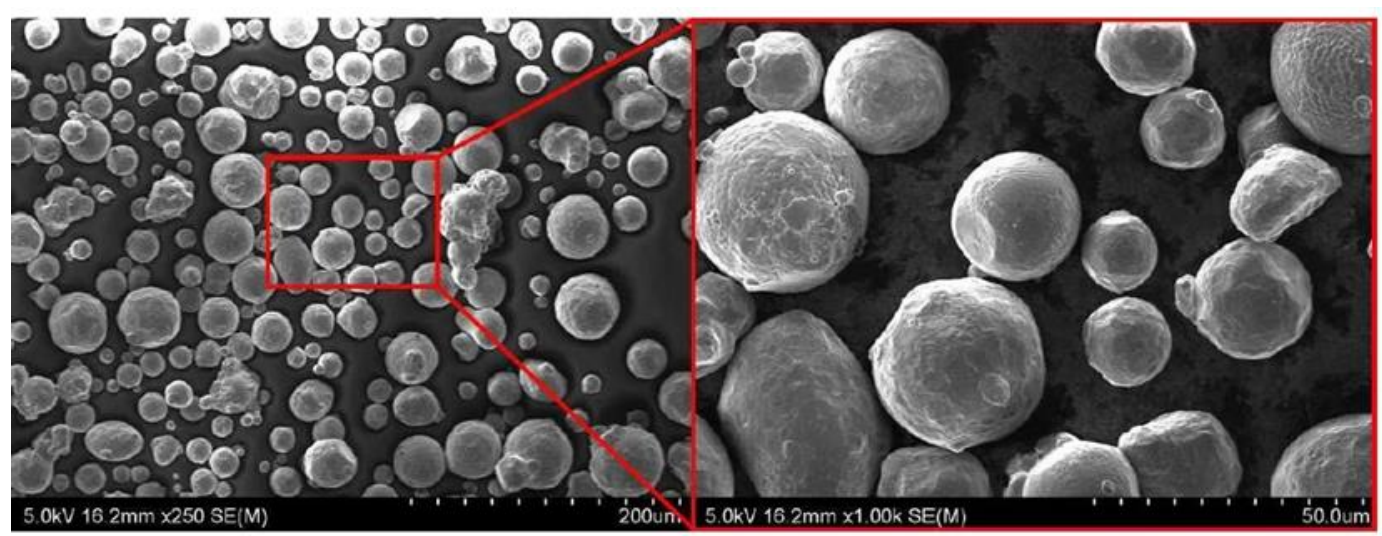

Figure 2. SEM image of scalmalloy used in this research

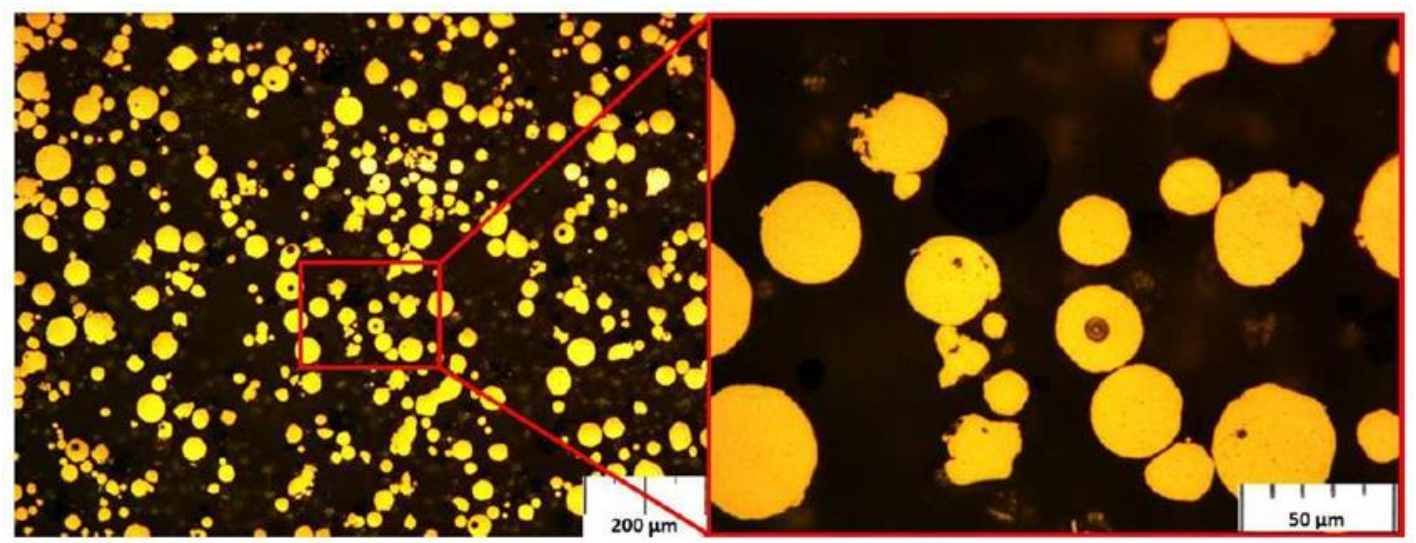

Figure 3. Optical images of scalmalloy powder particle cross-sections

The cross-sections of the powder in figure 3 reveal inner porosity for some particles. $7.1 \%$ of 966 optically evaluated powder particle cross-sections showed inner gas pores, whereby the pores' spherical morphology confirmed the origin as gas entrapment during melt solidification. The pore size range was significantly smaller than the size of the particles, Microhardness results of the powder particles were done on 30 different powder particles for accuracy. The average hardness value was found to be 91.4 $\pm 9.7 \mathrm{HV} 0.005$. The hardness values found in the present research are lower than the findings reported by Palm et al. (2010) of 125 to $175 \mathrm{HV} 0.005$, however, an alloy with higher Scandium content of $1.4 \mathrm{wt} \%$ was used, while the Scandium content for the present research is $0.65 \mathrm{wt} \%$. Hence, hardness values are lower due to the lack of Al3(Sc1- xZrx) 
precipitates caused by lower scandium content. The maximum solubility of Sc is $0.6 w t \%$ with a cooling rate of $100 \mathrm{~K} / \mathrm{s}$, which exceeds that of gas atomization, whereby aluminum solid solution for high solidification rates such as gas atomization is usually between 105 to $107 \mathrm{~K} / \mathrm{s}$ for aluminum alloys with a particle size of 50-5 $\mu$ m (Palm et al. 2010; Zakharov, 2003). In summary, the powder characterization shows good processability for SLM spherical powder size and even distribution. The absence of Al3(Sc1-xZrx) is also beneficial as these do not need to be melted, hence the formation of a highly supersaturated aluminum solid solution is more likely to be achieved. However, it must be noted that inner porosity found in some powder particles may cause the inner porosity of manufactured parts detrimentally affecting mechanical properties.

\section{Verification of SLM process parameter}

The first build job of five cube samples was produced with SLM process parameters based upon findings by Spierings et al. (2016). Samples produced using 240 and 280J/mm3 showed swelling on the top surface of the cubes, indicating that the energy volume density is too high. Visual inspection of the surfaces' of the samples is significantly better than those reported in Spierings, Dawson, Heeling, et al. (2017) where 200W laser power was used. Dimensional accuracy was examined for each cube sample, where energy volume density appears to have barely any effect. All five samples (Figure 4) are 0.1 or $0.2 \mathrm{~mm}$ larger than the CAD model used and distances between opposing sample surfaces in the y-direction are slightly larger than in the x-direction. For easy identification of each sample, a number is placed on the sample, which may cause discrepancies. Standard VDI 3405 Part 3 recommends a tolerance for dimensional accuracy of $\pm 0.1 \mathrm{~mm}$. Swelling and larger dimensions are caused by the attraction and melting of adjacent powder particles next to laser scan tracks due to surface tension of the melt pool and melt pool motion with a laser scan (Yadroitsev et al. 2010).

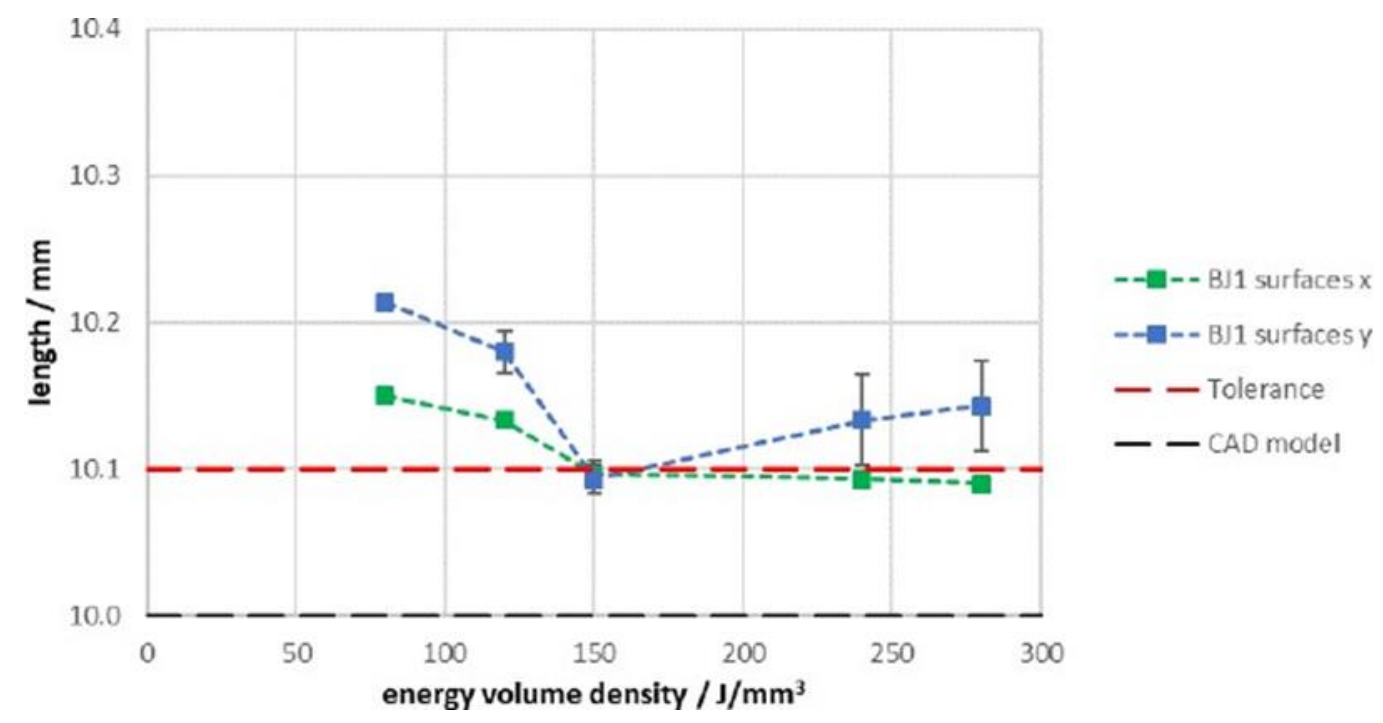

Figure 5. Comparison of Archimedes density measurements and metallographic density-dependent upon energy volume density (enlarge too small)

Dimensional accuracy of the cube samples for both the surface and sides of the cubes built using 80 and 280J/mm3 were compared. For both samples, the top surfaces show hatch and scan directions of the last built layer. Top surface roughness is visually low with some partially melted powder particles. Higher energy densities appear to result in lower surface roughness for the horizontal surfaces, while vertical side surfaces exhibit higher surface roughness and more incomplete melting of powder particles, which are to be expected according to Strano et al. (2013). The swelling was visible on the top surface of the cube sample produced using $280 \mathrm{~J} / \mathrm{mm} 3$ and vertical 
surfaces show open micro-porosity. Figure 5 summarises the results of Archimedes and metallographic relative density measurements to evaluate inner porosity. Samples built using 80 and $120 \mathrm{~J} / \mathrm{mm} 3$ exceed the desired value of $99 \%$ relative density, while all other samples resulted in densities between 95-99\%. Error percentage between Archimedes and metallographic relative densities are lower than $2 \%$ with a standard deviation of samples with lower relative densities are significantly higher. According to figure 5, no maximum is visible, and the curve is shifted to lower energy volume densities. The results for the Archimedes method show lower standard deviations than the metallographic relative densities. The sample produced using $80 \mathrm{~J} / \mathrm{mm} 3$ is the only sample exceeding $100 \%$ density. This may be possible as the theoretical density of the measured sample may be higher than the theoretical value of $2.67 \mathrm{~g} / \mathrm{cm} 3$. The cause may also be due to the evaporation of elements such as aluminum and magnesium during SLM. With a high laser power of 400W combined with the low melting and evaporation temperatures of aluminum and magnesium, this is the most likely cause. Errors may also have occurred while performing the Archimedes density test. Mass in air, the density of ethanol may be too high, and/or sample mass in ethanol and ethanol temperature may be too low. The sample mass in the air is assumed, ethanol temperature was measured, and the density of ethanol was calculated using equation (2). As these values are assumed or calculated, these may cause such discrepancies. Standard deviations also indicate that Archimedes' values are slightly too high among all samples and, may be caused by a systematic error. Also, the cube samples produced with lower energy volume densities of 100 , 120 , and $150 \mathrm{~J} / \mathrm{mm} 3$ showed an inhomogeneous lateral pore distribution and a significantly wider range of pore size distributions indicated by higher standard deviations of the metallographic relative densities. Irregular pore morphology, larger pore sizes, and high energy volume densities, porosity is most likely caused by evaporation. All samples exhibited micropores randomly distributed among powder particles, whereby powder-derived porosity has occurred. The shift in the processing window compared to Spierings et al. (2016) may be caused by different SLM machines used, higher laser power, different laser focus diameters, and also the metallic powder in question. Doubling the laser power seems to result in different relative densities of the Scalmalloy parts even when energy volume density is kept constant.

Microhardness results can be seen in figure 6. It appears that increasing energy volume density increases hardness. Lower energy volume densities result in less heat in the melt pool and high thermal conductivity of solidified layers underneath results in higher cooling rates. Samples produced using an energy volume density less than $120 \mathrm{~J} / \mathrm{mm} 3$ results in high suppression of Al3(Sc1-xZrx) precipitates, whereby a supersaturated solid solution of aluminum is formed. These are optimal conditions where subsequent age hardening may be performed on Scalmalloy. Etched cross-sections of the samples can be seen in figure 7. The microstructure of the sample is the following findings from the literature as mentioned earlier. A detailed investigation of the microstructure was not performed due to the intense etching of the user agent.

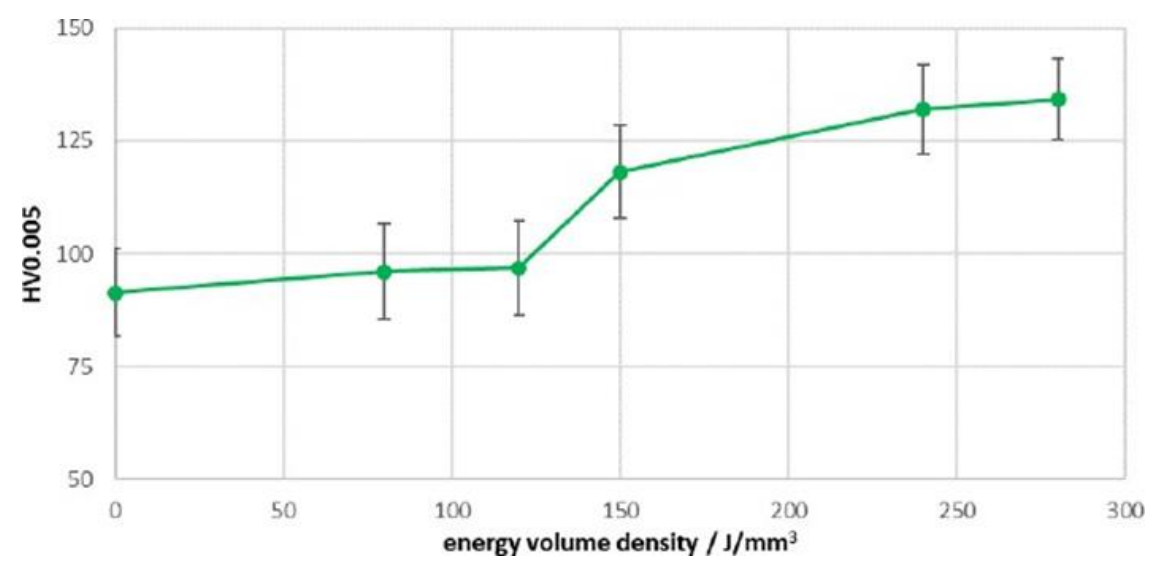


Figure 6. Microhardness Results of cube samples with changing energy volume densities

In summary, a partial optimal SLM process parameter window with relative densities exceeding $99 \%$ and energy volume densities between 80 and $120 \mathrm{~J} / \mathrm{mm} 3$ was found for a laser power of 400W. These were confirmed both with the Archimedes density method and metallographic cross-sections. This partial window also results in the lowest microhardness comparable to powder particle microhardness. Further investigations are necessary to provide sufficient data for a complete window as no maximum value for relative density and no lack of fusion were detectable.

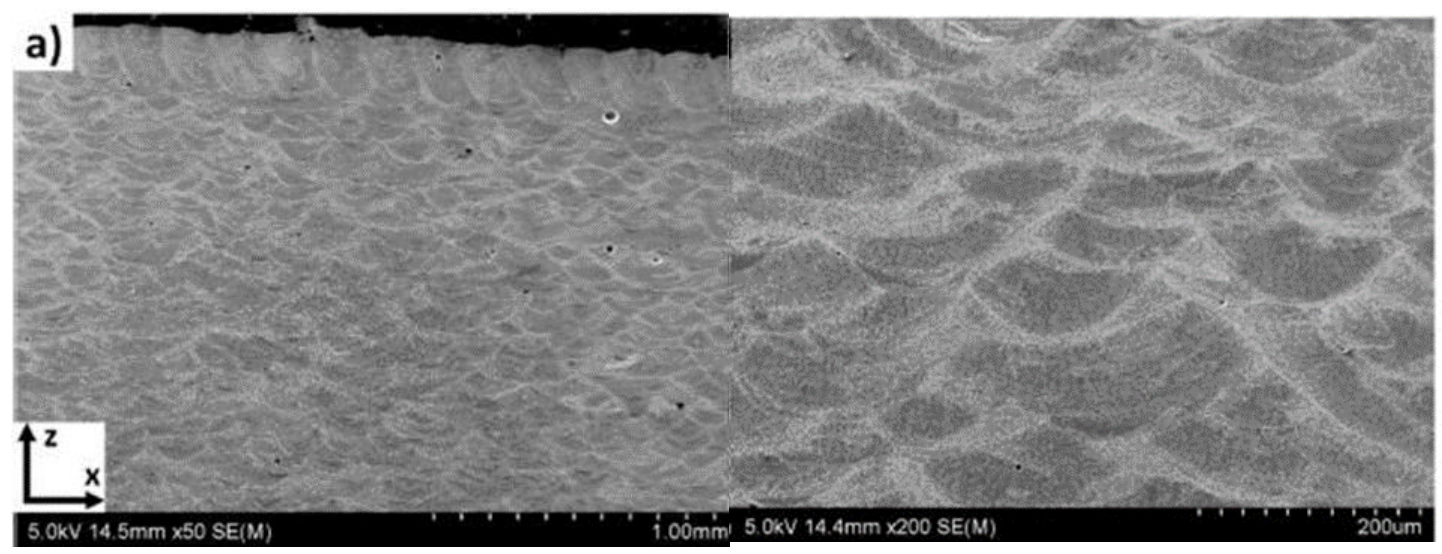

Figure 7. Etched cross-section of $80 \mathrm{~J} / \mathrm{mm}^{3}$

\section{Investigation of SLM process parameter window}

In order to complete investigations for an optimal SLM process parameter window for relative densities exceeding 99\%, the same experiments used in the previous section will be executed an additional time with modified energy volume densities. This second build job produced five cube samples. No swelling is visible upon the samples, but surface roughness is apparent on the top surfaces especially for those with decreasing energy volume density. Dimensional accuracy (shown in figure 8) for the sample produced using $80 \mathrm{~J} / \mathrm{mm} 3$ agrees with the previous build job indicating inter-build reproducibility is high. The sample produced using $30 \mathrm{~J} / \mathrm{mm} 3$ exhibits a deviation between $x$ and $y$ direction of more than the recommended deviation of $0.1 \mathrm{~mm}$, while its dimension in the $\mathrm{x}$-direction, is almost equal to the CAD model. Again, it must be noted that opposing faces of the cube sample are marked with identification numbers. For relative densities (shown in figure 9), the maximum value is indicated for $80 \mathrm{~J} / \mathrm{mm} 3$ and relative densities decrease with lower energy volume densities. The Archimedes method shows $99 \%$ relative density is exceeded for energy volume densities of $40-110 \mathrm{~J} / \mathrm{mm} 3$. Standard deviations of the Archimedes mean values are lower than the metallographic mean values, except for relative densities exceeding $99 \%$. For both samples produced using $80 \mathrm{~J} / \mathrm{mm} 3$, their relative densities are identical and higher than $100 \%$ confirming the assumption of a systematic error.

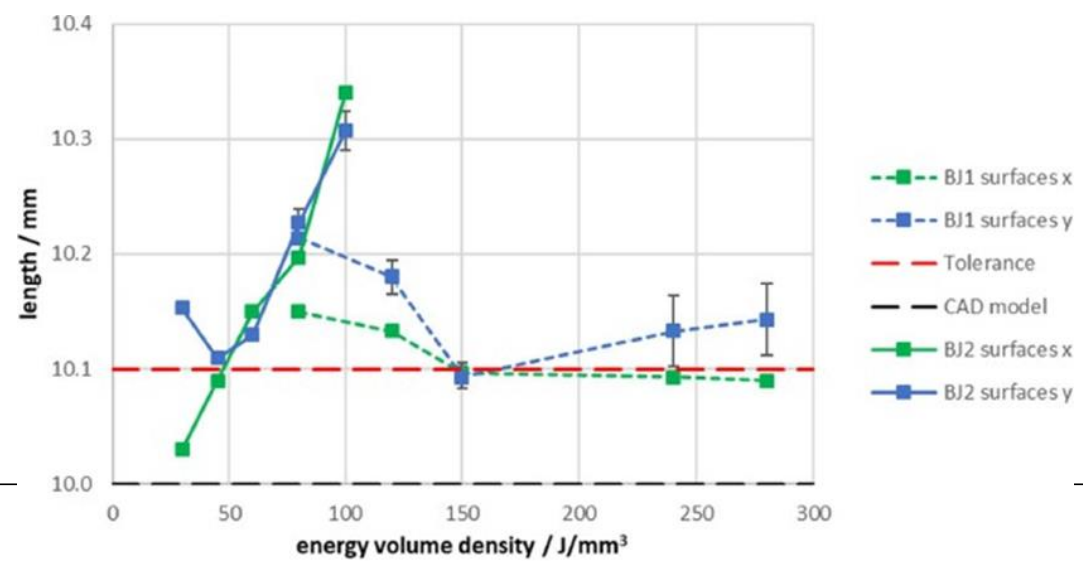


Figure 8. As-built dimensional accuracy of cube samples in different directions in comparison of changing energy volume densities (too small ...enlarge)

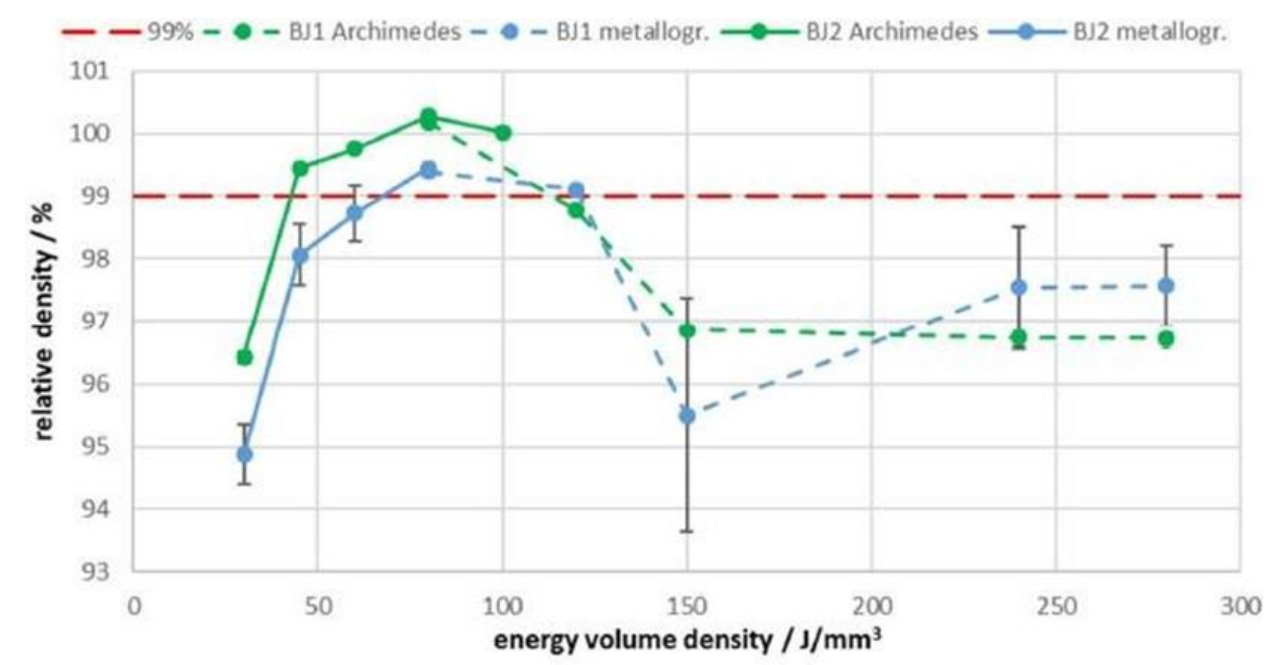

Figure 9. Comparison of relative Archimedes Density and metallographic density with changing energy volume densities (too small ...enlarge)

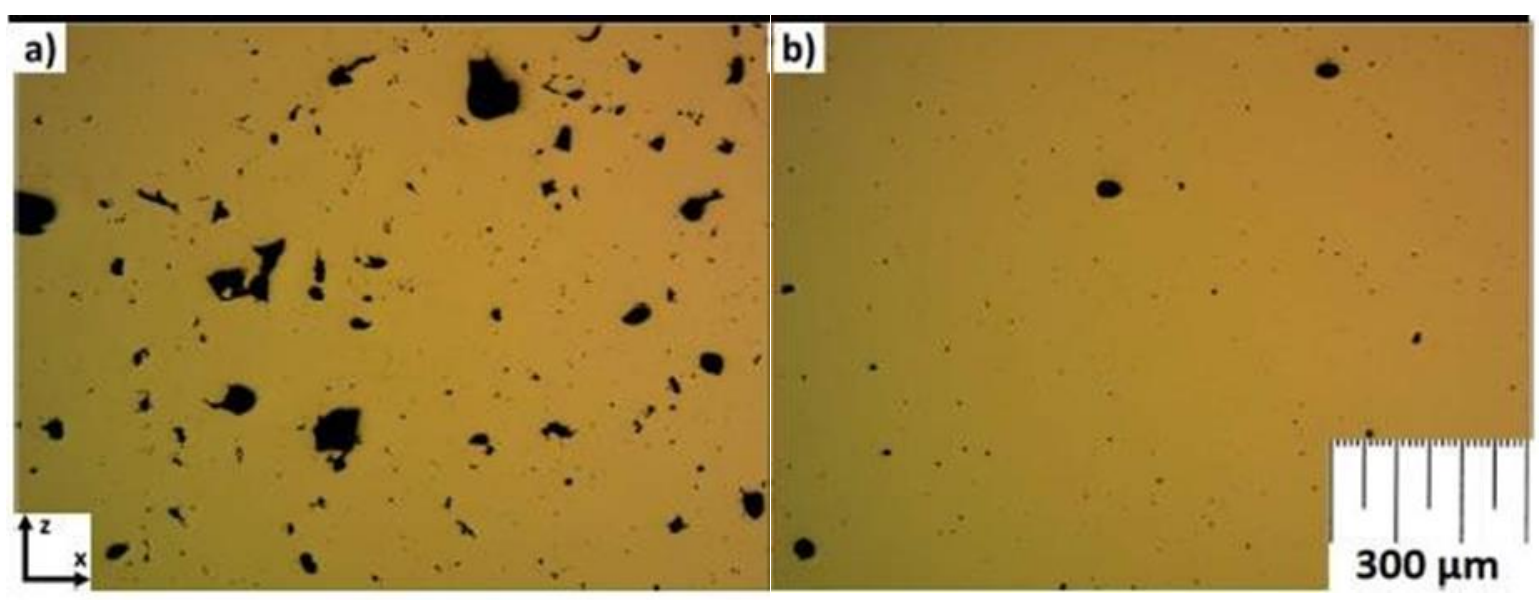

Figure 10. Optical Images of cube sample cross-sections for different energy volume densities - a) $30 \mathrm{~J} / \mathrm{mm} 3 \mathrm{~b}$ ) $80 \mathrm{~J} / \mathrm{mm}^{3}$
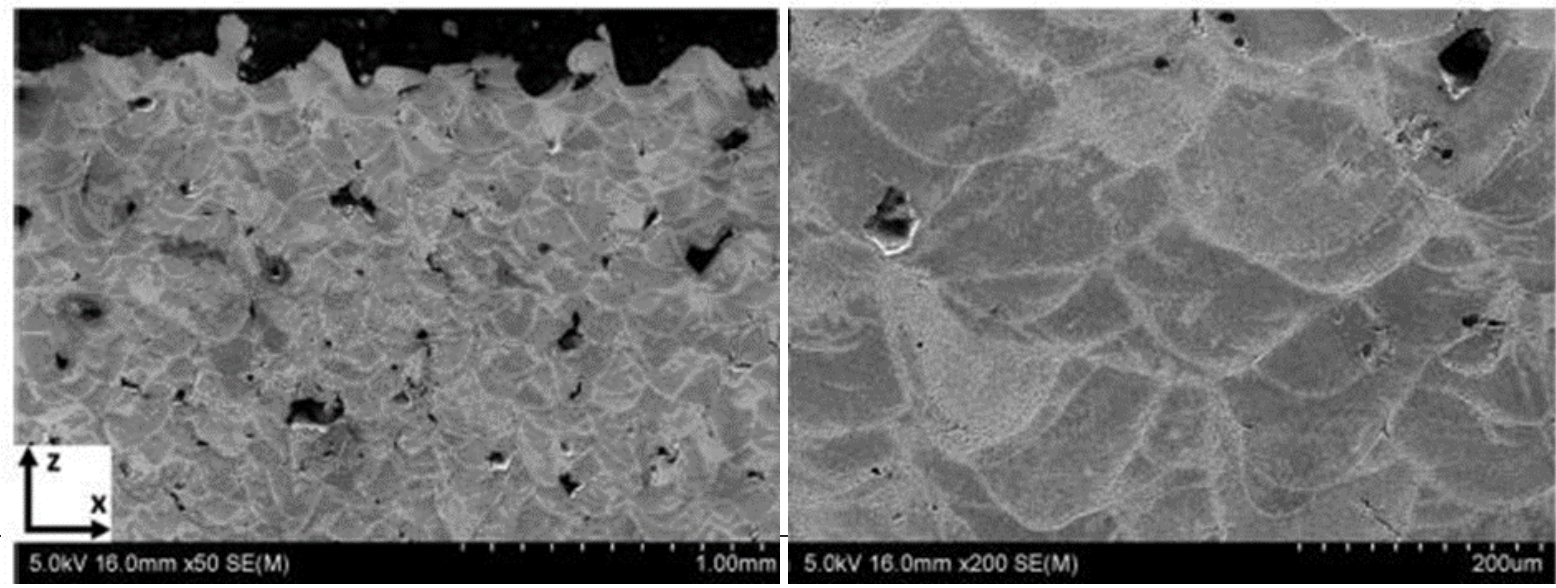
Figure 11. SEM Images of etched cross sections for 30J/mm3 energy volume density

Optical micrographs of cube cross sections in figure 10 show irregular-shaped pores 20$100 \mu \mathrm{m}$ in size with microporosity for low volume energy density. Lack of fusion is the most likely cause due to low energy input. SEM images in figure 11 further confirm these findings as porosity and incomplete melting is visible. In a study by Koutny et al. (2018), a laser power of 325-400W was used along with a slightly different composition alloy of Scalmalloy. Relative densities were reported to be less than $98 \%$ and the optimal SLM process parameters were found to be $375 \mathrm{~W}$ laser power and $69 \mathrm{~J} / \mathrm{mm} 3$, thus agreeing with the results found in this research. Figure 12 shows microhardness results for both build jobs and powder particles. Microhardness results for the $80 \mathrm{~J} / \mathrm{mm} 3$ from both samples are identical along with their standard deviations. This indicated inter-build reproducibility is high for Scalmalloy and the SLM machine. All other values are consistent with data of build job 1 . Microhardness results for the $30 \mathrm{~J} / \mathrm{mm} 3$ energy volume density is decreased, yet the standard deviation is increased, however, this is thought to be due to high inner porosity.

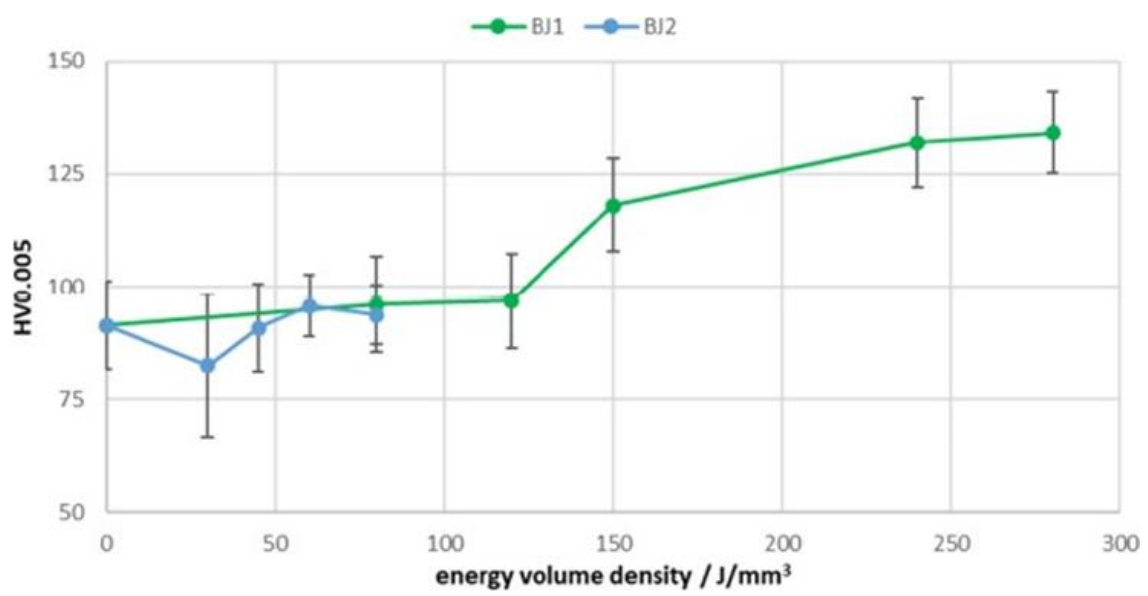

Figure 12. Microhardness results of cube sample cross-sections with changing energy volume densities including build job 2 results. $0 \mathrm{~J} / \mathrm{mm} 3$ refers to powder particle microhardness results

In summary, the full optimal SLM process parameter window regarding relative densities exceeding $99 \%$ for the chosen fixed laser power of $400 \mathrm{~W}$, the layer thickness of $30 \mu \mathrm{m}$ and hatch distance of $150 \mu \mathrm{m}$ for processing Scalmalloy was found to be between $70-110 \mathrm{~J} / \mathrm{mm} 3$ energy volume densities. Microhardness of the samples built using these parameter sets shows a high potential for subsequent aging heat treatment and beneficial mechanical properties for the SLM parts. SLM inter-build reproducibility is assumed to be high, based on relative density, microhardness, and dimensional accuracy of two cube samples built-in subsequent build jobs.

\section{Reproducibility and influence of layout position}

75 cube samples $10 \times 10 \times 10 \mathrm{~mm}$ were built using the optimal found process parameters. Each build job consisted of an array of $5 \times 5$ cube samples with $10 \mathrm{~mm}$ dimension placed in between the building platform mounting holes. Archimedes calculated relative density values for these samples ranged from 99.6\%-100.4\%. Samples were marked with identification numbers to indicate its position on the build platform. Archimedes density measurement indicates that local minima are in the center of the build platform and a slightly increased relative density values for $\mathrm{x}$ and $\mathrm{y}$ 
coordinates. Standard deviations of mean values for density measurements do not follow any obvious local pattern and are within the range of $\pm 0.0-0.2 \%$. Judging by high homogeneity of mean values and global low standard deviations, these contributing system properties can be considered homogenous and constant. For Scalmalloy samples produced using optimal found SLM process parameters and laser power of 400W show excellent intro- and inter-build reproducibility concerning relative density.

\section{Conclusion}

This research investigated an SLM process parameter window for relative densities exceeding 99\%. This process parameter was derived and showed a shift to lower energy volume densities in comparison with literature data for $200 \mathrm{~W}$ laser power. Relative densities for manufactured samples were measured using the Archimedes method and based upon metallographic cross-sections. The optimal process parameter window for $400 \mathrm{~W}$ laser power, $30 \mu \mathrm{m}$ layer thickness, and $150 \mu \mathrm{m}$ hatch distance was found in the range of $40-110 \mathrm{~J} / \mathrm{mm} 3$ energy volume density based upon the Archimedes method. Dimensional accuracy shows signs of anisotropy concerning $\mathrm{x}$ and y directions, which should be considered for thin-walled and complex parts. No significant influence of layout position was recorded as all samples exceeded $99 \%$ in relative density. Hence Scalmalloy can be SLM-processed with scan speeds more than doubled compared to literature data and productivity increased significantly. Microhardness testing of samples also indicates desirable suppression. of Al3(Sc1-xZrx) precipitates during this SLM process, whereby there is a high potential for subsequent aging. In further work, Scalmalloy aging conditions and work hardening conditions will be explored using the parameters found in this research

\section{Acknowledgment}

The authors of this article would like to thank Ross Jacobs for producing the additively manufactured samples, Mark Masterton for assisting in mounting and polishing samples, and also Yuan Tao for assisting in SEM and Optical Microscopy

\section{References}

Aboulkhair, N.T., Simonelli, M., Parry, L., Ashcroft, I., Tuck, C. \& Hague, R. (2019). 3D printing of aluminium alloys: additive manufacturing of aluminium alloys using selective laser melting. Progress in Materials Science, 106,100578.

Aversa, A., Marchese, G., Saboori, A., Bassini, E., Manfredi, D., Biamino, S., Ugues, D., Fino, P. \& Lombardi, M. (2019). New aluminum alloys specifically designed for laser powder bed fusion: A review. Materials (Basel),12(7), 1-19.

Best, J., Maeder, X., Michler, J., \& Spierings, A. (2018). Mechanical anisotropy investigated in the complex SLM-processed Sc- and ZrModified Al-Mg Alloy Microstructure. Advanced Engineering Materials, 21(2), 13-20.

Chituc, C.-M. (2017). XML interoperability standards for seamless communication: An analysis of industry-neutral and domain-specific initiatives. Computers in Industry, 92-93, 118-36.

DebRoy, T., Wei, H.L., Zuback, J.S., Mukherjee, T., Elmer, J.W., Milewski, J.O., Beese, A.M., Wilson- Heid, A., De, A. \& Zhang, W. (2018). Additive manufacturing of metallic components - Process, structure and properties. Progress in Materials Science, 92, 112-224.

Hanzl, P., Zetek, M., Bakša, T. \& Kroupa, T. (2015). The Influence of Processing Parameters on the Mechanical Properties of SLM Parts. Procedia Engineering, 100, 1405-13.

Harun, W.S.W., Kamariah, M.S.I.N., Muhamad, N., Ghani, S.A.C., Ahmad, F. \& Mohamed, Z. (2018). A review of powder additive manufacturing processes for metallic biomaterials. Powder Technology, 327,128-51.

Kaiser, M.S., Datta, S., Roychowdhury, A. \& Banerjee, M.K. (2014). Effect of prior cold work on tensile properties of Al-6Mg alloy with minor scandium additions. Canadian Metallurgical Quarterly, 53(4),486-93.

Koutny, D., Skulina, D., Pantělejev, L., Paloušek, D., Lenczowski, B., Palm, F. \& Nick, A. (2018). Processing of Al-Sc aluminum alloy using SLM technology. Procedia CIRP, 74, 44-8.

Li, N., Huang, S., Zhang, G., Qin, R., Liu, W., Xiong, H., Shi, G. \& Blackburn, J. (2019). Progress in additive manufacturing on new materials: A review. Journal of Materials Science \& Technology, 35(2), 242-69. 
Li, R., Chen, H., Zhu, H., Wang, M., Chen, C. \& Yuan, T. (2019). Effect of aging treatment on the microstructure and mechanical properties of Al-3.02Mg-0.2Sc-0.1Zr alloy printed by selective laser melting. Materials \& Design, 168,107668.

Li, R., Wang, M., Yuan, T., Song, B., Chen, C., Zhou, K. \& Cao, P. (2017). Selective laser melting of a novel Sc and Zr modified Al-6.2 Mg alloy: Processing, microstructure, and properties. Powder Technology, 319,117-28.

Maamoun, A.H., Xue, Y.F., Elbestawi, M.A. \& Veldhuis, S.C. (2018). Effect of Selective Laser Melting Process Parameters on the Quality of Al Alloy Parts: Powder Characterization, Density, Surface Roughness, and Dimensional Accuracy. Materials (Basel, Switzerland),11(12), 2343.

Olakanmi, E.O., Cochrane, R.F. \& Dalgarno, K.W. (2015). A review on selective laser sintering/melting (SLS/SLM) of aluminium alloy powders: Processing, microstructure, and properties. Progress in Materials Science, 74, 401-77.

Palm, F., Leuschner, R., Schubert, T. \& Kieback, B. (2010). Scalmalloy ${ }^{\circledR}=$ A unique high strength ALMgSc type material concept processed by innovative technologies for aerospace applications, Conference: Proceedings of the World Powder Metallurgy Congress and Exhibition, World PM 2010. At: florence.

Polmear, I., Qian, M., StJohn, D. \& Nie, J.-F. (2017). Light Alloys : Metallurgy of the Light Metals, Elsevier Science \& Technology, United Kingdom: Oxford.

Schmidtke, K., Palm, F., Hawkins, A. \& Emmelmann, C. (2011). Process and mechanical properties: applicability of a scandium modified al-alloy for laser additive manufacturing. Physics Procedia,12, 369-74.

Singh, S., Ramakrishna, S. \& Singh, R. (2017). Material issues in additive manufacturing: A review. Journal of Manufacturing Processes, $25,185-200$.

Spierings, A., Schneider, M. \& Eggenberger, R. (2011). Comparison of density measurement techniques for additive manufactured metallic parts. Rapid Prototyping Journal, 17,380-6.

Spierings, A.B., Dawson, K., Heeling, T., Uggowitzer, P.J., Schäublin, R., Palm, F. \& Wegener, K. (2017a). Microstructural features of Scand $\mathrm{Zr}$-modified Al-Mg alloys processed by selective laser melting. Materials \& Design, 115, 52-63.

Spierings, A.B., Dawson, K., Kern, K., Palm, F. \& Wegener, K. (2017b). SLM-processed Sc- and Zr- modified Al-Mg alloy: Mechanical properties and microstructural effects of heat treatment. Materials Science and Engineering: A, 701, 264-73.

Spierings, A.B., Dawson, K., Uggowitzer, P.J. \& Wegener, K. (2018). Influence of SLM scan-speed on microstructure, precipitation of Al3Sc particles and mechanical properties in Sc- and Zr-modified Al-Mg alloys. Materials \& Design, 140, 134-43.

Spierings, A.B., Dawson, K., Voegtlin, M., Palm, F. \& Uggowitzer, P.J. (2016). Microstructure and mechanical properties of as-processed scandium-modified aluminium using selective laser melting. CIRP Annals, 65(1), 213-6.

Strano, G., Hao, L., Everson, R.M. \& Evans, K.E. (2013). Surface roughness analysis, modelling and prediction in selective laser melting. Journal of Materials Processing Technology, 213(4), 589-97.

Vock, S., Klöden, B., Kirchner, A., Weißgärber, T. \& Kieback, B. (2019). Powders for powder bed fusion: a review. Progress in Additive Manufacturing.

Wong, K.V. \& Hernandez, A. (2012). A Review of Additive Manufacturing. ISRN Mechanical Engineering, 2012, 1-10.

Yadroitsev, I., Gusarov, A., Yadroitsava, I. \& Smurov, I. (2010). Single track formation in selective laser melting of metal powders. Journal of Materials Processing Technology, 210(12), 1624- 31.

Yap, C.Y., K. Chua, C., L. Dong, Z., H. Liu, Z., Q. Zhang, D., Loh, L.E. \& Sing, S.L. (2015). Review of selective laser melting: Materials and applications. Applied Physics Reviews, 2(4), 041101. doi: 10.1063/1.4935926

Zahner, L.W. (2019). Aluminum Surfaces : A Guide to Alloys, Finishes, Fabrication and Maintenance in Architecture and Art, John Wiley \& Sons, Incorporated, Newark, United States.

Zakharov, V.V. (2003). Effect of scandium on the structure and properties of aluminum alloys. Metal Science and Heat Treatment, 45(7), 246-53.

Zhang, B., Li, Y. \& Bai, Q. (2017). Defect Formation Mechanisms in Selective Laser Melting: A Review. Chinese Journal of Mechanical Engineering, 30(3), 515-27 